\title{
Key Considerations in the Development of a University High Performance Training Centre Business Framework
}

\author{
Francois Pieter Kotze \\ Department of Business Management, College of Economic and Management Sciences, University of South Africa, Pretoria, South Africa \\ Email address: \\ francoiskotze@sun.ac.za

\section{To cite this article:} \\ Francois Pieter Kotze. Key Considerations in the Development of a University High Performance Training Centre Business Framework. \\ International Journal of Sports Science and Physical Education. Vol. 6, No. 2, 2021, pp. 17-28. doi: 10.11648/j.ijsspe.20210602.11
}

Received: March 16, 2021; Accepted: March 27, 2021; Published: April 7, 2021

\begin{abstract}
Universities and colleges are under increased pressure to be self- sustainable and to rely less on government funding and generate more third-stream revenues. In sport, university High Performance Training Centres (HPTCs) are seen as key strategic assets to the university, but generally do not receive continuous direct funding from the universities and need to be self- sustainable in its own right. These centres support university sport in general but are also commercial entities that serve all target markets, including professional and recreational sport and fitness. The onus is on these HPTCs to be sustainable and even profitable, following normal business practices like sales and marketing and client service, with retained earnings being used for capital improvements and additions, as well as general operational expenses of the centres. Recently, university HPTCs across South and Southern Africa (and internationally) are on the increase, but there seems to be a lack in the consistency of business framework principles implemented by the different universities and colleges. The aim of this research is to develop and propose a standardised business framework specific to university HPTCs, which can be implemented to enhance the overall likelihood of sustainability and even profitability of the HPTCs, and also ensure that these HPTCs are less reliant on continuous university funding. The framework will align with specific micro, macro and meso level policy factors that have to be considered in the development of a university-specific business framework. The study proposes several Key Success Factors (KSF) to be considered in the development of the business framework. To reach the aim, various business practices and frameworks from university HPTCs were compared to non-university HPTCs, consisting of commercial and government- supported centres. In conclusion, a generic business framework is proposed, specific to the university and college sport environments.
\end{abstract}

Keywords: High Performance Training Centres, University, Business Framework, Policies, Key Success Factors

\section{Introduction}

In the professional era of sport and the emergence of sports management and sports science as independent disciplines, it has become increasingly important to manage sport on the basis of sound commercial business principles [3], with profitability being the key driver of any commercial business. High Performance Training Centres (HPTCs) still have to apply most of the same business principles, operations and functions as any other commercial entity. The ultimate success of the HPTCs should be driven by these sound business principles and organisational structures, like any other for-profit organisation. HPTCs are mostly seen as a support service to the university environment as a cost centre [26], without much emphasis on commercialisation or profitability. In saying this, HPTCs still have to apply most of the same business operations and functions as a commercial facility [2]. There are still sales and marketing functions, financial statements have to be drawn up and analysed and, in some instances, investors, or shareholders, need to see a return on their investments. Therefore, it is critical that HPTCs, whether associated with a university, commercially driven, or supported by national governments, have a sound business framework that aligns with normal commercial business practices. Kotze and Ferreira [16] stated that university HPTCs can be feasible and even profitable, if these centres follow a structured business plan and consider several key factors that can lead to long-term sustainability.

Fundamentally, differences in the way that HPTCs are owned and managed will occur as a result of the corporate 
governance models in use by different centres worldwide. These differences are largely attributed to different ideological models and perspectives of governments, which can be large stakeholders of HPTCs, especially in Continental Europe [22, 27]. Bohlke [4] echoes this view, stating that the way that sport is organised in countries will vary according to a Continental (European) or Anglo-Saxon perspective.

Bohlke [4] is of the opinion that attention should be paid to the way that sport is managed across countries and continents, before any comparison is drawn between the business models or frameworks of HPTCs. Essentially, he distinguishes between two distinct models: the shareholder (Anglo- Saxon) model and the stakeholder (Continental) model. The shareholder model of corporate governance states that the sole purpose or goal of the organisation is to earn profits. This model is mostly seen in commercially- driven HPTCs, where a return on investment is key. On the other hand, in a stakeholder model the focus is on managing and balancing budgets, rather than profit maximisation. Sustainability is the key driver of the business and is more applicable to government-funded entities. Both perspectives were taken into consideration in this study and investigated the primary goals, roles and objectives of HPTCs within university, national and international sports structures and concludes with the proposal of a generic business framework. Previous studies have failed to address HPTC business frameworks, especially at university level, and focused more on policy-level decisions [10].

\section{Purpose of the Research}

The purpose of the study is to investigate the current business practices implemented by various HPTCs, including university, commercial and government- supported HPTCs. A comparison was drawn between the business practices of private commercial facilities and government-funded facilities, compared to university HPCs. To conclude the study, a generic conceptual business framework is proposed that could assist directors and/or owners of university HPTCs to establish and manage a sustainable and profitable business unit within a tertiary institution environment. This study could further contribute to further studies in the field of sports management in general at university level, and further also in establishing appropriate business models for the various sports entities at universities. At present, very little comprehensive research and literature are available on the business models of HPTCs in the field of sports management, as HPTCs are relatively new in South Africa

\section{Literature Review}

The literature review will address two aspects that are important to consider before a business framework can be proposed for university HPTCs. Firstly, it is important to define a business framework from a theoretical perspective, compared with a business strategy, model and plan. Secondly, the theories on policy decision-making in a sport context needs to be considered. To do this, the SPILSS theory on policy- level decision-making [9] and a high sport model that originated in the USA were used as a theoretical framework [21]. These two theories on policy- level decision-making will be briefly discussed later in this section, following the discussion on business frameworks. Furthermore, these two theories will be used as theoretical bases to propose policylevel decisions that need to be made in a HPTC business framework.

Understanding of a business strategy, model, plan and framework

For the purposes of this study, it was imperative to have a good understanding of the concepts business strategy, business model, business plan and business framework. These four concepts were identified and are described in the following section.

Business strategy and business model are two terms used interchangeably, but enormous differences exist between these two concepts. Casadesus-Masanell and Ricart [7] argue that a model and a strategy are two independent terms. In their view, a strategy refers to the actual choice of business model through which the firm can compete in the marketplace. The primary objective of the business strategy is in effect to choose the appropriate business model [7], and only then conceptualise and implement the business plan. This strategy will typically include the business mission (which is the key objective of the strategy), its product and market scope (where the business competes) and its basis for differentiation (how the business will compete). These components will comprise the core strategy [12]. A business strategy is the cornerstone of any business and a clear strategy will make any other business decisions fairly simple [24]. Traditionally, according to work published by Porter in 1998, a business can choose any of the following three generic strategies [24]:

Cost leadership: A cost leadership strategy can be achieved by charging customers less than what the industry charges for the same or very similar products and services. This is normally achieved by reducing costs.

Differentiation: A differentiation strategy requires an organisation to deliver products and services that have a perceived higher value than similar products or services offered by other competitors in the marketplace. A superior-quality product or service normally achieves this perceived higher value.

Focus: The focus strategy can further be categorised as cost focus or differentiation focus. With a cost focus, a narrow product line is determined with the emphasis on cost. With a differentiation focus, there is focus on a narrow product line, striving towards product or service differentiation within the market.

A business model, on the other hand, reflects the strategy of the business and addresses the way it operates and creates shareholder value. Where the strategic direction is set in the overall business strategy, the business model is typical to an industry and does not dictate the operations of a business unit 
within an industry [12]. Kühn and Louw [17] state that a business model is a construct that tries to simplify the business undertakings and make it more tangible. Magretta [18] states that business models emerged when personal computers and spreadsheets became popular. Managers now had the tools to monitor various aspects of a business to see how these numbers affect the bottom-line profits of a business. In contrast, a business strategy will highlight how an organisation can do better than its competitors and not only describes how the business functions, as is pertinent in the description of a business model. Key features of each are discussed in more detail further on in this chapter. A business may have an excellent business model, but may not have a clear business strategy, resulting in a lower measure of success [11].

Each business needs a plan that identifies and depicts how the organisation conducts its business. Without such a plan, plans are aimless, and all efforts will be fruitless. Teece [28] argues that all businesses make use of business plans, whether implicitly or explicitly. It is more than just a way of doing business. It also needs to meet customer demands and create a competitive advantage. Typical questions that will need answering in a business plan include the following [28]:

What is the product or service offering of the business?

At what cost can the business produce a specific product or service?

What will be the selling price of the product and/or service?

What industries will the business target and how will the business achieve a competitive advantage in this sector?

What resources does the business require to deliver a product and/or service?

Ideally, each business needs to have appropriate answers to these questions posed and proceed to formulate the answers in a structured way in a business plan or a business model. It is furthermore also imperative that the business regularly review the plan and measure the successful implementation of that which was planned against actual results and actions. The Business Dictionary defines a framework as a broad overview, or an outline or skeleton, of interlinked items that supports a particular approach to an objective [6]. This framework can be altered at any time by adding or deleting items. According to Kühn and Louw [17], a framework consists of the following key features:

A framework must be generic enough to be used in a variety of industries.

The process of moving through the framework must be rational and follow a structured decision-making process.

The framework should be practicable within various industries.

The framework should contain a comprehensive approach to the problem by integrating various fields of discipline.

The framework should be flexible and adjustable to be used in rather specific situations.

The business framework usually differs from a business strategy, a business model and business plan. The framework is the conceptual model that will lead to the formalisation of the business model and the business plan, based on the strategy of the business. Hough et al. [14] state that the model is the storyline that the management of the business sets that indicates how and where revenues will be generated. This formal document is preceded by the ongoing development of the business framework. As soon as the framework is found to be able to yield positive results, the business plan will be formalised and implemented.

According to Kühn and Louw [17], a business framework consists of the following key features:

A framework must be generic enough to be used in a variety of industries.

The process of moving through the framework must be rational and follow a structured decision-making process.

The framework should be practicable within various industries.

The framework should contain a comprehensive approach to the problem by integrating various fields of discipline.

The framework should be flexible and adjustable to be used in rather specific situations.

This research concludes with the proposal of a business framework that could assist university HPTCs to be sustainable and profitable business units.

Theoretical models developed to manage high performance sport

Several authors, including De Bosscher et al. [10] and Smolianov and Zakus [21], have developed theoretical models that propose critical factors that need to be considered, implemented and achieved to ensure sporting success, especially at international level. The aim of this section is to briefly describe two theories in particular, based on the level of policy decision- making. Similarly, at the conclusion on this research, a business framework that is also based on the three policy levels of decision making- micro, meso and macro levels will be proposed.

According to De Bosscher et al. [9], on a sports policy level there are several factors that may lead to international sporting success. The SPLISS (Sports Policy Factors Leading to International Sporting Success) framework was developed and focuses on three policy levels of decision-making:

Micro level (operational practices): The focus is on obtaining information from athletes and coaches in their immediate and close environments.

Meso level (tactical design): The focus is on organisational and sports policies relating to the management of sport mostly from a federal/ government perspective.

Macro level (strategic structure): The focus is on comparisons between countries based on population, wealth and other cultural factors. It also focuses on economic, social and cultural aspects of nations, including wealth, political ideologies and religion.

Similarly, Smolianov and Zakus [21] proposed a theory to analyse sports development when referring to the High-performance Management Model in university sports. This model also proposes three levels of policy decision-making, similar to the model proposed by De Bosscher et al. [9]: 
Micro level: Operations, processes and methodologies for developing athletes. The successful functioning of the micro-level elements depends largely on high-quality equipment and facilities.

Meso level: Infrastructure, personnel and services enabling sports programmes. The successful implementation of the meso-level elements will depend largely on effective partnerships to obtain sufficient resources.

Macro level: Socio-economic environment, legislation, cultural and organisational influences. The successful implementation of macro-level elements depends heavily on government policy factors regarding high-performance sport and the overall socio-economic environment

\section{Methodology}

Both quantitative and qualitative data-collection techniques were used in this research in a sequential, exploratory manner in a mixed-method research approach. This mixed- method approach was used to cross- validate and corroborate the research findings. The first phase in the research process was to collect all quantitative data, followed by the qualitative data collection process.

\subsection{Quantitative Data Collection}

An online questionnaire was developed and distributed to university and non-university (consisting of privately owned commercial and government- supported centres) HPTCs. Non- university HPTCs included primarily members of the Association of Sport Performance Centres [1]. The questionnaire included a variety of questions, including both open- ended and close- ended Likert scale questions. No questionnaire existed at the time of this study that could have potentially gathered the information required for this particular study. The ASPC had 65 member centres and eight individual members in 2015, totalling 73 centres. Outside of the ASPC, the questionnaire was also distributed to randomly selected university HPTCs mainly in South Africa and the UK as well as commercial HPTCs in South Africa. All the data collected were from $2014-2016$.

\subsection{Qualitative Data Collection}

To collect qualitative data, semi-structured interviews were held with participating centres, following the quantitative data collection. These interviews were conducted either in person, telephonically or via Skype. Interviews were only held with those centres that indicated a willingness to participate in further research after completing the online questionnaire. Personal interviews were held with HPTCs mainly in South Africa and the UK, where the researcher personally visited various centres for the purpose of conducting the interviews and general observations in natural conditions to gain a further insight into the general operation of these centres. All interviews were conducted and recorded by the primary researcher. No relationship was established between the researcher and the interviewee prior to the interview. Permission to record the interviews was obtained from the interviewees completing agreements prior to the interview taking place at the individual centres. The participants also completed informed consent forms. Centres that participated in the research under the auspices of the ASPC did so under the confidentiality agreement of the ASPC. In cases were audio recordings of interviews were not permitted, the researcher kept detailed notes of the interviews.

The final phase in collecting data included the secondary data collection which involved the collection of mostly quantitative data [19]. This data was extracted from existing sources and included documents such as, yearbooks, financial reports, earlier research, websites and personal records.

Data analysis and interpretation were completed using both quantitative and qualitative analysis. SPSS was used to calculate the descriptive statistics of the data extracted from the various HPCs. Qualitative data were gathered using semi-structured interviews and the findings were analysed. All the data gathered were coded during the research (grouped into conceptual categories) to guarantee the anonymity of the centres. Furthermore, where HPTCs were visited in person, field notes and observations were also used in the data-collection process.

\section{Results}

The primary goals of HPTCs are to create elite training destinations where athletes can fully prepare for national and international competitions. The vision statement and strategic objectives of the HPTCs provide strong evidence of this. To achieve excellent service delivery to athletes in creating elite training destinations in all types of HPTCs, several key services are offered. These services include sports scientists, recovery facilities and high-performance gymnasiums. It appears that the majority of the HPTCs offer these services, either directly under the umbrella of the HPTC, or through contracted personnel.

Equally important is the role that the university HPTC plays in the development of student athletes. The vision statements and strategic objectives of HPTCs further emphasise the roles that the HPTCs play in the development of athletes, whether student athletes (65\% of participants) or national-/international-level athletes (96\% of participants). This is especially the case with government-funded centres. University HPTCs play a prominent role in the development of student athletes, but at the same time, the HPTCs are seen as a strategic asset to the university.

It is further also evident that not all the centres have a responsibility or an obligation to generate any additional funds, other than those funds that they receive from their respective national governments. It is also not common for government-supported centres to drive profitability and profit maximisation. Although not a priority at government supported HPTCs, it certainly is a priority at university and commercial centres. It is evident from the discussion above 
that university HPTCs primarily have an important role to fulfil in both university and national sports structures. The study found vast differences exist in the overall goals and strategic objectives of HPTCs globally. Equally important, there are centres that rely heavily on ongoing financial support from national governments. These centres focus mainly on the development and preparation of national and international athletes for international competitions. Other centres (including both commercial and university HPTCs) are more profit-driven and have to execute extensive sales and marketing activities to drive revenues for the centres to be sustainable and profitable.

As a result of the varying visions and strategic objectives of the centres, it is not possible to have one optimum business model that would apply to all centres. The framework presented in this research specifically applies to university HPTCs. University HPTCs have to operate within a very strong tertiary institution environment, which has a profound impact on the behaviours of the HPTCs. The availability of sports facilities could be an environmental constraint of the HPTCs. At HPTCs, especially at universities, sports facilities are shared between the HPTCs, the university sports codes and a recreation division, sports federations and athletes and do not fall under the direct ownership of the HPTC. Where the facilities do not fall directly under the management or the ownership of the centres, the athletes and members of the centres have very limited access to these facilities. Owning the sports facilities allows for more autonomous decision making.

In the same way, as a monetary constraint, university HPTCs in South Africa generally receive start-up capital or funding from the universities, but ongoing direct financial support from the universities is weakening and a stronger emphasis is placed on the HPTCs to generate second(commercialisation), third- (sponsorship) and fourth(donations) stream revenues. A number of HPTCs are liable for full facility rentals payable to the universities, with no indirect financial support (payment of utility bills by the universities). Some universities also have student gymnasiums, as well as an HPTC (for example, the University of Pretoria has both a student gymnasium on the main campus and an HPTC closer to the university sports fields). Substantial revenues can be generated from student membership fees should these facilities be combined into one facility that can cater for everybody's needs, as in the case of the University of Bath and Stellenbosch University.

\section{Discussion \& Conclusion}

Vast differences exist in the overall goals and strategic objectives of HPTCs globally. Equally important, there are centres that rely heavily on ongoing financial support from national governments. These centres focus mainly on the development and preparation of national and international athletes for international competitions. Other centres (including both commercial and university HPTCs) are more profit-driven and have to execute extensive sales and marketing activities to drive revenues for the centres to be sustainable and profitable.

As a result of the varying visions and strategic objectives of the centres, it is not possible to have one optimum business model that would apply to all centres. The framework presented in this research specifically applies to university HPTCs. This framework is not a guarantee for financial sustainability and profitability but may enhance the likelihood thereof. This research has shown that there are substantial differences in the overall goals and strategic objectives of HPTCs across the globe, which makes the suggestion of a 'good-for-all blueprint' impossible. The suggested framework below is specifically applicable to university HPTCs.

Table 1. Proposed framework detailing key success factors (KSF) for university HPTCs.

\begin{tabular}{|c|c|c|c|}
\hline Level of policy decision-making & Environment & KSF \# & KSF description \\
\hline \multirow{5}{*}{ Micro level (HPTC) } & \multirow{5}{*}{ Internal to HPTC environment } & KSF 1 & Professional management structures \\
\hline & & KSF 2 & Membership options \\
\hline & & KSF 3 & Direct sales and marketing function \\
\hline & & KSF 4 & Asset ownership/partnerships \\
\hline & & KSF 5 & Services offered \\
\hline \multirow{8}{*}{ Meso level (university) } & \multirow{8}{*}{$\begin{array}{l}\text { External to HPTC environment, but } \\
\text { internal to university environment }\end{array}$} & KSF 6 & Start-up capital/funding \\
\hline & & KSF 8 & Access to student accounts \\
\hline & & KSF 9 & Licensing and trademarks \\
\hline & & KSF 10 & Accommodation \\
\hline & & KSF 11 & Indirect university financial support \\
\hline & & KSF 12 & Research \\
\hline & & KSF 13 & Supported human resource and finance functions \\
\hline & & KSF 14 & Access to sports facilities \\
\hline \multirow{5}{*}{ Macro level (national government) } & \multirow{5}{*}{$\begin{array}{l}\text { External to university environment, } \\
\text { but internal to national environment }\end{array}$} & KSF 16 & Cities \\
\hline & & KSF 17 & National accreditation \\
\hline & & KSF 18 & Lotteries \\
\hline & & KSF 19 & Public-private partnerships \\
\hline & & KSF 20 & Government-supported district academies of sport \\
\hline
\end{tabular}


Table 1. Continued.

\begin{tabular}{llll}
\hline Level of policy decision-making & Level of ownership/control & Probability of sustainability & Probability of profitability \\
\hline & High & Medium & Medium \\
& High & High & Medium \\
& High & High & High \\
& Medium & High & High \\
& Medium & High & Medium \\
& Low & High & High \\
& High & High & High \\
& Medium & High & High \\
& Medium & High & Medium \\
& Medium & High & High \\
& High & Medium & Medium \\
& Low & Medium & Medium \\
& Medium & Medium & Medium \\
& High & High & Medium \\
& Medium & Medium & Medium \\
& Low & Medium & Medium \\
& Medium & Medium & Medium \\
& Low & Medium & Medium \\
\hline
\end{tabular}

The business framework proposed above is a new framework that is presented in conclusion of this research as a result of the limited previous research that has been done on the financial sustainability and profitability of HPTCs. The framework, from a policy decision perspective, aligns with the micro-, meso- and macro-level factors of the sports policy models presented by De Bosscher et al. [10] and Smolianov and Zakus [21]. The policy decisions are taken at university HPTC level (the microenvironment), university level (the meso environment) and national government level (the macro environment). The KSFs refer to the decisions made by the different environments that could have a profound effect on the sustainability and the profitability of the HPTCs.

At micro level, the university HPTC will generally have a high level of ownership over the decisions that are made on the general business practices of the HPTC. On the contrary, the level of ownership or control that the HPTC has over the decisions that are made at both university (meso) and national (macro) levels are significantly less. The university HPTCs, especially in the South African context, have no ownership or control over policy decisions made by national government. These centres can only effectively control whether they would willingly engage in public-private partnerships with government. The first step in implementing this framework would be to address all the high level of ownership factors, as the HPTC has more control over these factors. It is not necessary for all the high-level factors to be implemented, but the probability of sustainability and profitability proportionately increases with the successful implementation of each factor.

The policy decisions taken at each of the micro, meso and macro levels will have a profound impact on the sustainability and the profitability of the HPTCs, indicated in the last two columns of the framework under 'Probability of sustainability' and 'Probability of profitability'. Long-term sustainability will enhance the probability of profitability, and vice versa.

KSFs of university HPTCs

The business framework proposed in conclusion to this research study also focuses on the micro, meso and macro levels in the same way as the two models summarised above. From a university HPTC point of view, the levels are defined as follows:

Micro-level factors: These are the policy decisions and actions that each individual HPTC can implement internally to the organisation, irrespective of the policy decisions that are made at either meso or macro level.

Meso-levels factors: These are the policy decisions made at university level, with or without consulting the HPTC. The university HPTC typically requests that these policy decisions be made in favour of the sustainability of the HPTC These decisions are not under the direct control of the HPTC itself.

Macro-levels factors: These are the policy decisions and actions that are taken at provincial and/or national government level to which both universities and university HPTCs have to adhere. These decisions are normally made without consulting either the university HPTCs or the universities.

Each of these level factors is discussed in detail in the next section.

\section{Micro-level factors}

The micro-level factors are all factors that are within the direct control of the HPTC. These are all the internal policy decisions that fall within the authority of the HPTC and include the five factors detailed below.

KSF 1: Professional management structures

Bester [3] states that with the emergence of sports management and sports science as independent disciplines, it has become increasingly important to manage sport based on sound commercial business principles. It is proposed that even at university level, HPTCs should make use of professional managers to manage and direct business 
operations, both operationally and strategically. Too often, the university HPTCs make use of service-delivery experts to manage the business, with little or no management expertise or experience. These service-delivery experts may have strong backgrounds in sports science or physiotherapy, for example, but management need to be appropriately qualified and experienced in the field of management. Centres should adequately budget for the remuneration, commissions and incentives for setting up professional management structures. In addition to the management of the centres, experts in sales and marketing should actively drive revenues in designated targets markets.

KSF 2: Membership options

It is critical for the HPTC to allow for a range of different membership options, derived from the various target markets that the HPTC serves. The majority of the typical HPTC membership types are seasonal. For example, in South Africa, the typical university annual calendar stretches from February to November. Revenues are drastically reduced in June and July, as well as December and January due to the students and university sports teams being on summer holidays. During December and January, the climate in South Africa lends itself to hosting visiting international teams and individual athletes, which will earn the HPTC additional revenues. Public memberships allow for continued sustainable income all year round. It is proposed that membership options include options for students, university sports codes, university staff and alumni, national- and international-level athletes and the public. These membership options will also largely depend on other internal HPTC factors, including the size of the facility, member usage statistics, the range and number of equipment available and the staff available to service all the members.

KSF 3: Direct sales and marketing function

A direct sales and marketing function is indispensable for any HPTC. It is critical that adequate sales and marketing expense budgets are set and approved annually. This study showed that the mean sales and marketing budgets for participating HPTCs were €49 214 in 2014, €51 981 in 2015 and $€ 63951$ in 2016. It appears that sales and marketing budgets are increasing annually. Direct sales consultants need to be employed on a full-time basis to actively drive membership revenues, using a mix of membership options highlighted in 6.1.2. It is further proposed that minimum daily activity levels are set for each consultant, in line with the normal fitness industry standards. Typically, daily targets include 24 new contacts, six new appointments with prospective members, followed by four price presentations that may yield two sales. It is further proposed that a detailed monthly, weekly and even daily sales and marketing plan be followed, accompanied by set budgets that will allow the activities to take place. Monthly sales incentives and commissions are payable on the achievement of set targets.

It was further found that only $33 \%$ of HPTCs have a structured sales and marketing plan. Setting and implementing a direct sales and marketing strategy and plan will increase the likelihood of long-term sustainability.
Equally important, sales and marketing activities need to be directed at the most profitable target markets. These include, primarily, university students and student athletes, followed by the public and then national-/international-level athletes and sport federations. University staff and alumni are secondary target markets, as these two areas do not yield the same results as the student populations. Revenues from national- and especially international-level athlete are more seasonal than revenues generated from university students, unless accommodation can be provided to these athletes.

KSF 4: Asset ownership/partnerships

The initial capital required to start a HPTC was highlighted throughout this research, coupled with the high cost of specialised equipment to provide a diverse range of specialist services. HPTCs have to find alternative ways in which start-up capital is raised and assets are owned. Should sufficient start-up capital not be provided by the universities or should continued financial support not be provided by either local/national governments or universities, acquiring additional assets may prove to be difficult.

It is proposed that strategic partnerships and alliances be forged with key equipment suppliers, which will enable university HPTCs to lease specialised equipment directly financed by the suppliers. Several university HPTCs have these partnerships in place and the suppliers provide very competitive interest rates. The lease agreements also include an extended warranty and service agreement, which saves costs on the HPTC expense lines (no further maintenance expenses). The lease agreements should include quarterly inspections and preventative maintenance visits. Therefore, HPTCs also save on the depreciation expense line item in their financial statements.

KSF 5: Services offered

Furthermore, statistical analysis of the services offered by the HPTCs identified ten specialised services offered by the HPTC, ranging from strength and conditioning to recovery and accommodation services. A research study conducted by Davis and Henwood [8] found that associate members of the ASPC mostly provide strength and conditioning and physiotherapy services to athletes, followed by sports medicine. In the same way, earlier research by Bohlke and Bahr [4] has shown that centres provide a variety of specialised services at HPTCs, either directly from the centres themselves or in partnership with external service providers. It is proposed that services offered by HPTCs include access to a high-performance gymnasium, accommodation and meals, sports scientific and medical services, recovery services and physiotherapy.

\section{Meso-level factors}

The meso-level factors are all factors that are within the direct control and ownership of the university but are not under the control of the HPTC. These include all the policy decisions that are taken by the university, either in consultation with the HPTC or without, and include the ten detailed below.

KSF 6: Start-up capital/funding

From a university perspective, it is recommended that 
start-up capital/funding be received from university strategic funding, in the same way as other university sports facilities that receive start-up funding directly from the university. This can be done either through an interest-free long-term loan or as a donation. Such funding is a once-off occurrence and universities do not have to further contribute to ongoing direct operational expenses of the HPTC.

KSF 7: Ownership

It is critical that the HPTC fall under the direct ownership of the university. In some instances, it was found that the HPTC is a separate registered entity (private company) within the university structure. This is also acceptable. Seeing as universities are tax-exempt entities, it would be beneficial for the HPTC to fall under the direct ownership of the university, in the same way that other sports facilities do. In this way, the HPTC can apply indirectly for tax-exempt status.

The gymnasium is a critical element that has to be owned by the HPTC. It is further also recommended that formal service level agreements be concluded with all other areas that do not fall under the direct ownership of the HPTC. These agreements need to clearly stipulate the terms and conditions of access, usage, availability and rates of usage. In this way, all parties will have certainty and access to other facilities is communicated in a clear and transparent manner.

KSF 8: Access to student accounts

It was found that university students as the primary target market to drive revenues, with the student population accounting for more than $75 \%$ of its annual revenues. Key to this success is the fact that HPTCs can have the right to add all student membership fees directly onto the students' annual accounts at the university, in the same way that sports clubs can add annual membership fees onto these students' annual accounts. This needs to be done directly via coded API (Application Programming Interface) protocol. The benefits of this include the following:

The risk of debt to the HPTC is very low. In general, the universities are responsible to collect all outstanding debts on students' accounts. This responsibility does not lie with the different units or clubs.

The risk of debt is further reduced by the fact that the parents of students are liable for the accounts, and the risk is not placed on the students to ensure payment thereof. A higher return is received where parents of students are liable for gymnasium fees.

Full contractual student membership fees are received in advance by the HPTC from the university, which may improve the cash flow of HPTCs.

A coded API protocol removes the hassle of doing sales and loading membership fees manually onto students' accounts. The API protocol should include a reporting feature to accurately audit payments and receipts.

Student membership fees provide a solid foundation of revenues to the HPTC in times when revenues from other sources may be low. For example, revenues received from international athletes are very seasonal.

KSF 9: Licensing and trademarks
Earlier it was highlighted that the HPTC needs to fall under the ownership of the university. In addition to being owned by the university, the HPTC can access the rights to branding and trademarks of the university through a formal licensing agreement. This licensing agreement will allow the HPTC to formally communicate its affiliation to the university through aggressive co-branding. In South Africa, universities carry a very strong brand name and reputation, and the brand image of the HPTC is enhanced through this affiliation. In the internal university environment, all stakeholders (including students, student athletes, staff and alumni) will have a strong affinity to the centre should it be branded as a university asset.

It is proposed that a licensing agreement be concluded between the HPTC and the university that will allow the HPTC to access all university brands, logos and trademarks. It is further proposed that the licensing fee be computed at $10 \%$ of the total revenues of the HPTC, excluding sponsorships and donations income, on condition that the licence fee:

1) Shall not exceed $50 \%$ of the total audited net operating income of the HPTC; and

2) Is subject to the HPTC generating a net profit and is not applicable should the HPTC be in a loss-making position.

The licensing agreement will provide a steady income stream for the university in lieu of a full commercial facility rental and utilities. The university will also have a stake in the HPTC and would want to ensure that the overall university brand image is protected and that the HPTC is a sustainable business unit. Lastly, it is proposed that retained income be used by the HPTC to invest back into the facility in leasehold improvements and asset acquisitions.

KSF 10: Accommodation

In the SPLISS model, De Bosscher et al. [10] emphasise the importance of training facilities, including accommodation, in Pillar 6. In analysing the infrastructure element in the role of HPTCs, Bohlke and Bahr [4] also highlight the importance of accommodation facilities for athletes. Stier [25] states that the accommodation facilities at TuksSport HPTC contributes substantially to the overall revenues of the HPTC and are critical to the financial success of the business.

When planning for and initiating a HPTC, it is recommended to plan for sufficient accommodation facilities for anchor tenants (athletes for NSFs, for example), student athletes and visiting national and international athletes. It is imperative that these facilities, including meals, be managed in a professional manner. Income can be generated all year round by directly marketing and selling to the various target markets.

KSF 11: Indirect university financial support

KSF 6 highlighted the importance of universities providing start-up capital/funding for the HPTC. It was further also recommended that ongoing direct financial support by the university (to cover all operational expenses of the HPTC) is not necessary. The university, however, can financially contribute indirectly to the HPTC. It is recommended that 
universities be liable for all utilities of the HPTC, in the same way that the university is liable for the utilities of sports departments in general. These utilities include water and electricity. Equally important is that universities provide indirect financial support by allowing the HPTC to make use of its human resources and financial functions, in the same way that these services are also provided to the general university sport environments.

HPTCs can negotiate with the universities for building maintenance assistance at preferential rates. The planning of the overall specialised leasehold improvements is, however, still the responsibility of the HPTC. The building in which the HPTC is situated belongs to the university and the facilities management function could be extended to the HPTC, in the same way that the universities maintain other university assets. The net book value of the leasehold improvements could be sold back to the university at a later stage.

In the same way, it is imperative that the HPTC not be liable for a full commercial facility rental, in lieu of the annual licensing fee payable by the HPTC.

KSF 12: Research

University HPTCs are in a unique position to offer valuable research opportunities that can benefit all the stakeholders of a university HPTC. Athletes, including student athletes and national-/international-level athletes, are continuously looking for ways to gain a competitive advantage over other competing athletes. Research could improve the overall performance of athletes and draw the attention of athletes, who may use other facilities. In the same way, continuing research could be used as an effective marketing tool to attract athletes to university centres. Furthermore, university HPTCs could collaborate with other university sports departments to attract more students (especially postgraduate students) who will potentially enhance the ranking of the university on official rankings such as the Times Higher Education list.

KSF 13: Supported human resource and financial support functions

KSF 4 highlighted the importance of indirect financial support from the university. Therefore, it is recommended that the university provide all human resource and finance support, which will allow the HPTC to concentrate on its primary business purposes. It has to be noted that the HPTC still needs to be involved in these two processes. For example, the recruitment of a strength and conditioning coach should be done on the backbone of the university recruitment system, but the final placement decision needs to rest with the HPTC. In the same way, the HPTC could use the backbone of the university finance function, especially in the governance of the tender process, to acquire additional assets.

KSF 14: Access to sports facilities

One of the major constraints experienced by HPTCs in a tertiary institution environment is the availability of sports facilities. There are several reasons for this. Firstly, sports facilities do not regularly fall under the ownership of the HPTC. The research results indicated that sports facilities fall under the direct ownership of only $10.34 \%$ of the HPTCs. This causes the HPTC to have less control over the availability and the general management of the sports facilities. In addition, it was found that the sports facilities fall under the direct management of only $12.07 \%$ of HPTCs, causing the HPTCs to have even less control over the sports facilities.

It is recommended that university HPTCs generally have more access to sports facilities, especially to drive additional revenues, by playing a key role in the overall development of student athletes and, more importantly, national- and international-level athletes. Priority should be given to these groups on a regular basis, and not only during university holidays. It is further recommended that all sports facilities be booked on an online booking and payment system to ensure enhanced efficiency and effectiveness. Preferential rates need to be given to all facility bookings made by the HPTC to ensure sufficient opportunities to increase profit margins.

KSF 15: Dual careers of student athletes

The literature review provided evidence that Canada and the Netherlands are strong proponents of the dual careers of athletes. Henwood [13] states that in Canada, the athletes at universities are athlete students and not student athletes. This implies that although the academic career of the athlete is important, focus is placed on the athletic career and not the academic career as first priority. Athletes have up to 10 years to gain a formal university qualification while being a professional athlete. Van Gelder [29] states that in the Netherlands strong emphasis is placed on the athletic career of the athlete, but that the academic career of the athletes is also of high importance.

In the South African university context, the primary emphasis is on the academic career of the athlete whilst at university. Student athletes have only three years to complete their normal undergraduate studies, while they are expected to also perform well in their athletic career. The relationship between the university and student athlete is short-lived.

To conclude, it is recommended that university policies make it possible for student athletes to complete undergraduate degrees in five years instead of three years. Both the university and the student athletes will benefit. This policy decision will allow the athletes to focus on their athletic development during a crucial age period. This policy decision will also allow the university to use the brand image of the athletes as an effective marketing tool to attract other student athletes and students alike.

Macro-level factors

The macro-level factors are all factors that are not within the direct control or ownership of the university or the HPTC. These factors include all the policy decisions that may be taken by provincial and/ or national governments, with or without consulting the HPTCs or the universities, and include the five factors detailed below.

KSF 16: Cities

Bohlke [5] states that in Germany, the city of Berlin is instrumental in the overall success of the OTC Berlin, by 
providing both infrastructure and financial support to the centre. Van Gelder [29] states that in the Netherlands the cities mostly provide infrastructure support to the CTOs. To conclude, due to the excessively high start-up costs of HPTCs because of the size of the facilities to accommodate all service providers and the high cost of specialised equipment, it is imperative that cities provide infrastructure support to develop HPTCs (in the absence of university strategic funding). Cities and municipalities may not directly invest in the brick-and-mortar facilities of a HPTC but can assist with other sports facilities that can also act as community sports and recreational facilities.

KSF 17: National accreditation

The research provided evidence that centres in the Netherlands had to follow a strict accreditation process in establishing the seven RTCs. Further to this, over 100 smaller facilities were accredited as spin-off clubs that mostly focus on strength and conditioning of elite-level athletes. In this light, it is recommended that a national accreditation system be implemented in South Africa, whereby SASCOC accredits facilities as bronze, silver or gold facilities. The value of financial support is directly linked with the level of accreditation of the HPTC. A gold facility would receive substantial financial support from government and bronze facilities would receive the least amount of financial support. Indirectly, HPTCs can strive towards better accreditation to gain more financially. In addition, it is recommended that the majority of athletes be sent to gold-accredited centres by SASCOC and the NSFs, potentially increasing revenues further.

\section{KSF 18: Lotteries}

It was found that $9 \%$ of HPTCs surveyed received start-up capital/funding directly from national lotteries. In South Africa, the National Lottery Commission stated that sport and recreation have received nearly $\mathrm{R} 4$ billion in financial support, but not to the HPTC structures directly. The National Lottery Commission further announced in 2018 that financial support to national sport federations will be limited to R5 million per year and R2.5 million per year for provincial sports organisations. Although the ongoing direct financial support from lotteries is not critical to the overall sustainability of HPTCs, it is recommended that the lottery makes a financial contribution to the planning and development of HPTCs. This will enhance the probability of long-term financial sustainability. Furthermore, lotteries could also indirectly financially support the HPTCs by providing funding to athletes via the national and/or provincial sports federations to make use of the services of the HPTCs.

KSF 19: Public-private partnerships

Public-private partnerships are negotiated between cities or provincial governments and the private sector or universities in this instance. Cities and municipalities in South Africa make limited contributions to the establishment of local sports facilities, mainly due to the high costs involved. A similar phenomenon is found with the development of HPTCs. Public-private partnerships could be a possible solution and may be implemented in one of two ways:

The centres and facilities are developed by public funds, and the private sector or universities are appointed to manage the said facilities, on sound business principles, on a profit-share agreement. In this way, both the public and the private partners or universities have a vested interest in the overall financial success of the facilities.

The centres and facilities are developed by a combination of public and private funds (or universities) and profits are shared equally once commitment to all operating costs has been done.

KSF 20: Government-supported district academies of sport

Lastly, the South African national government proposed in the Strategic Framework for Sport Academies in a 'Opex moet waai' (Opex must go) newspaper article that universities should act as district academies of sport where athletes can make use of all the service of the HPTC free of charge $[15 ; 23]$. In principle, this suggestion from the South African government is not sustainable, as any potentially sustainable programme needs to be financially supported. This support can be from a variety of sources, including (and probably most importantly) national government. The current mandate of university HPTCs neither allows services to be rendered free of charge, nor does it allow for talent identification and/or development.

\section{Limitations}

According to Kühn and Louw [17] limitations are a vital and inevitable aspect of any research study. These limitations may influence or limit the outcome of the study.

Several universities were non-responsive to the sharing of critical information, mostly pertaining to the financial performance of the various centres and programmes that the centres offer. This was especially the case with HPTCs from the United States of America. Of the centres that were prepared to share information, several centres did not complete the questionnaire in full, omitting key pieces of information specifically around business processes. A further limitation is seen in the vast differences in the overall goals and objectives of the various centres, as not all centres are commercially driven to be profitable. These centres are (sometimes entirely) funded by national governments with no commercial drive. The responsibility of these centres is restricted to managing budgets annually allocated to them and they primarily focus on athlete development. The results in the statistics could have been skewed as a result of this.

Language barriers may have contributed to the fact that not all the HPCs associated to the ASPC responded to the primary research instrument or the semi-structured interviews. These instruments were set in English and non-English-speaking nations (Germany, the Netherlands, Italy and Spain, in particular) struggled with the interpretation of some of the questions. These HPCs also could not express themselves in their mother tongue during the semi-structured interviews. 


\section{Recommendations}

From a policy point of view, it is strongly recommended that all five of the KSFs listed in the microenvironment should be implemented by university HPTCs as a priority. The probability of financial sustainability and profitability can be greatly enhanced by implementing these factors, even if the factors listed in the meso and macro environments are not implemented.

On meso level, it is highly recommended that at least the following critical KSFs be implemented at university policy levels:

KSF 6: Access to start-up capital/funding. It is recommended that the university, through either university strategic funding or sponsorships and donations, provide the start-up capital required for the HPTC. The university should also provide the building in which the HPTC will be situated.

KSF 8: Access to student accounts. It is highly recommended that university policy decisions allow the HPTCs to add student membership fees to the students' university accounts, in the same way that other university sports clubs load annual club fees onto these accounts.

KSF 9: Licensing and trademarks. Although paying a license and/or a trademark fee to the university is an additional expense on the income statement, it is recommended that HPTCs have access to the overall brand image and reputation of the university.

KSF 11: Indirect financial support from the university. Earlier in this chapter, it was discussed that the main functions of the HPTC are not in human resources and/or financial management. It is strongly recommended that the HPTC collaborate with the university human resource and finance functions. The costs of these two functions should lie with the university, and not the HPTC, in the same way that the university provides human resource and financial management support to other university sports codes.

The application of the business framework presented in this study can be tested in actual cases. The proposed framework has not been fully tested in the HPC environment. Future research can be done on the actual implementation of the framework at university level to measure the success of the proposed framework.

\section{References}

[1] Association of Sport Performance Centres (ASPC). 2017. Retrieved from https://www.sportperformancecentres. org. [Accessed 12 January 2017].

[2] Berrett, T. \& Slack, T. 2001. A framework for the analysis of strategic approaches employed by non-profit sport organisations in seeking corporate sponsorship. Sport Management Review, 4 (1): 21-45

[3] Bester, P. 2011. An environmental analysis of Cycling South Africa (2010). Unpublished MCom thesis. Pretoria: University of South Africa

[4] Bohlke, N. \& Bahr, H. 2015. The role of high performance centres. In Proceedings of the $9^{\text {th }}$ Association of Sport Performance Centres (ASPC) Conference, San Juan, 27-29 August.

[5] Bohlke, N. 2017. Personal Skype interview, 19 May, Mossel Bay.

[6] Business dictionary, 2017. Framework. Retrieved from https://www.businessdictionary.com/ definition/framework/html. [Accessed on 24 May 2017].

[7] Casadesus-Masanell, R. \& Ricart, J. E. 2010. From strategy to business models and onto tactics. Long Range Planning, 43 (2/3): 195-215.

[8] Davis, P. \& Henwood, D. 2017. Report of survey to investigate the functionality and capability of High Performance Training Centres (HPTCs). Unpublished.

[9] De Bosscher, V., De Knop, P., Van Bottenburg, M., Shibli, S. \& Bingham, J. 2009. Explaining international sporting success: An international comparison of elite sport systems and policies in six countries. Sport Management Review, 12 (3): 113-136.

[10] De Bosscher, V., Shibli, M., Van Bottenburg, M., De Knop, P. \& Truyens, J. 2010. Developing a method for comparing the elite sport systems and policies of nations: A mixed research methods approach. Journal of Sport Management, 24 (5): 567-600.

[11] Gidal, J. 2016. The Explainer: What is a business model? Harvard Business Review. Retrieved from https://www.hbr.org/video/5072479512001/the-explainer-wha t-is-a-business-model [Accessed 14 April 2018].

[12] Hamel, G. 2010. Leading the revolution. Strategy \& Leadership, 29 (1): 4-10. doi: 10.1108/10878570110367141.

[13] Henwood, D. 2017. Personal Skype interview, 17 September, Somerset West.

[14] Hough, J., Thompson, A. A., Strickland, A. J. \& Gamble, J. E. 2011. Crafting and executing strategy: Creating sustainable high performance in South Africa: Text, readings and cases. Second edition. Berkshire: McGraw-Hill Higher Education.

[15] Kok, M. 2015. Sam: Opex moet waai - Universiteitesleutel tot sukses. Rapport, 24 October: 18.

[16] Kotze, F. P. and Ferreira, E. J., 2020. Financial Sustainability and Profitability of High Performance Training Centres. South African Journal for Research in Sport, Physical Education \& Recreation, 42 (2).

[17] Kühn, W. J. \& Louw, L. 2018. A business model innovation framework for capturing white space opportunities. Unpublished MEng thesis. Stellenbosch: Stellenbosch University.

[18] Magretta, J. 2002. Why business models matter. Harvard Business Review, 80 (5): 86-92.

[19] Mouton, J. 2008. How to succeed in your master's \& doctoral studies: A South African guide and resource book. Pretoria: Van Schaik.

[20] Muller, S. F. 2018. Free higher education in South Africa: Cutting through the lies and statistics. Mail \& Guardian, 25 January. Retrieved from https://mg.co.za/article/2018-01-25-free-higher-education-in-s outh-africa-cutting-through-the-lies-and-statistics [Accessed 19 August 2018]. 
[21] Smolianov, P. \& Zakus, D. H., 2008. Exploring high performance management in Olympic sport with reference to practices in the former USSR and Russia. International Journal of Sport Management, 9 (2): 206-232.

[22] Sotiriadou, P. \& De Bosscher, V. 2013. Managing high performance sport. Milton Park: Routledge.

[23] South African Sports Confederation and Olympic Committee (SASCOC). 2012. South African sport academies. Pretoria. Government Printer.

[24] Spear, C. H. 2018. Why ODs need a business strategy: Having a defined business strategy is key to maximizing practice success. Retrieved from http://ink.galegroup.com/apps/doc/A525710199/AONE?u=27 uos\&sid=AONE\&xid=60ac62a5 [Accessed 10 May 2018].
[25] Stier, T. 2018. Personal interview, 15 March, Pretoria.

[26] Stellenbosch University Sport Performance Institute (SUSPI). 2014. Business Plan 2014-2018. Stellenbosch: Stellenbosch University.

[27] Sotiriadou, K. 2009. The Australian sport system and its stakeholders: Development of cooperative relationships. Sport in Society, 12 (7): 842-860.

[28] Teece, D. J. 2010. Business models, business strategy and innovation. Long Range Planning, 43 (2/3): 172-194

[29] Van Gelder, I. 2018. Personal Skype interview, 22 May, Stellenbosch. 